\title{
Prevalence and associated factors of genital chlamydia infection among Central Sexually Transmitted Diseases clinic attendees in Sri Lanka
}

De Silva R. N. D. ${ }^{1}$, Elwitigala J. P. ${ }^{2}$, Corea E. M. ${ }^{3}$, Attanayake H. A. S. ${ }^{4}$

\begin{abstract}
Introduction: Chlamydia trachomatis infection is the most prevalent bacterial sexually transmitted disease (STD). The aims of the study were to determine the prevalence of chlamydia among STD clinic attendees in relation to socio-demographic characteristics, clinical presentation and sexual and STD-related risk behavior, to measure the significance of associated factors and identify the most significant risk factors for chlamydia infection.
\end{abstract}

Method: A cross-sectional, descriptive study was done on 216 females and 252 males attending the Central STD Clinic. Endocervical swabs from females and urine from males were tested using the COBAS ${ }^{\circledast} \mathrm{TaqMan}^{\oplus}$ CT v2.0 rt-PCR. Socio-demographic data, clinical features and factors associated with infection were recorded. Significance of associated factors was determined using a Chi-square test and the most significant risk factors were identified using a binary logistic model.

Results: Prevalence of chlamydia among females was $17.1 \%$ (37/216) and among males was 5.2\% (13/252). Prevalence among female sex workers (FSWs) was 20.4\% (20/98, p $<0.001)$. Most infected females $67.6 \%$ $(25 / 37)$ were asymptomatic. In contrast, $61.5 \%(8 / 13, p=0.009)$ of infected males were symptomatic. Female gender, age $\leq 25$ years and providing or receiving commercial sex were the most significant risk factors $(\mathrm{OR}=3.942$, 95\% CI 1.896- 8.198, $\mathrm{OR}=2.142,95 \%$ CI $1.083-4.235$ and $\mathrm{OR}=1.978,95 \%$ CI 1.039-3.764, respectively).

Conclusions: Prevalence of chlamydia among female attendees is high and a high proportion of infections are asymptomatic, rendering syndromic management inappropriate. However, among males, symptomatic attendees were significantly more likely to be infected than asymptomatic. Targeted screening for chlamydia should be instituted among FSWs and the high-risk group (young females $\leq 25$ years) of the general population.

Keywords: genital chlamydia, sexually transmitted disease clinic attendees, Sri Lanka

Authors: Corresponding author; ${ }^{1}$ De Silva R. N. D, MBBS, Dip (Med Micro), MD, Senior Registrar in Microbiology, National STD/AIDS control programme, Sri Lanka. Email; nilushides@yahoo.com, https://orcid.org/0000-0002-4725-8987, ${ }^{2}$ Elwitigala J. P, MBBS, Dip (Med Micro), MD, Consultant Microbiologist, National STD/AIDS control programme, Sri Lanka.Email; jayanthi_lk@yahoo.com, 3Corea E. M, MBBS. Dip (Med Micro), MD, PhD, Senior Lecturer, Department of Microbiology, Faculty of Medicine, University of Colombo, Sri Lanka. Email; enokacorea@hotmail.com, ${ }^{4}$ Attanayake H. A. S, BSc, MSc, Scientist National STD/AIDS control programme, Sri Lanka Email; hemaliattanayake@gmail.com

Copyright

Acknowledgments: We thank all the participants of the study. We are also grateful to Dr Rohitha Muthugala and Dr Saranga Sumathipala and the laboratory and clinical staff of the Central STD clinic of the National STD/AIDS Control Programme

Conflict of interest: None,

Financial support: None,

Originality: This is an original research conducted at the Central STD clinic, NSACP, Colombo and presented at the 20th Annual Scientific Sessions of the Sri Lanka College of Sexual Health and HIV Medicine, 2015,

Submitted: 29.09.2018; Accepted: 23.11.2018 


\section{Full Article}

Introduction

Chlamydia trachomatis is the commonest sexually transmitted bacterial pathogen.(1,2) In 2012, the World Health Organization (WHO) estimated that the global prevalence of genital chlamydia infection among women aged 15-49 years was $4.2 \%$ [95\% uncertainty interval (UI): 3.7-4.7\%] and among men was $2.7 \%$ (95\% UI: $2.0-3.6 \%$ ). The estimated incidence was 131 million (100-166 million).(3) C. trachomatis serovars $\mathrm{D}-\mathrm{K}$ is the commonest aetiological agent in non-gonococcal urethritis (NGU) in males and females and nongonococcal cervicitis (NGC) in females. Untreated chlamydia infections give rise to individual health consequences and significant social and economic problems for society.

Very few studies on the burden of disease due to C. trachomatis have been conducted in Sri Lanka, predominantly in females attending sexually transmitted disease (STD) clinics.(4-9) The aim of this study was to address gaps in data, in Sri Lanka, by determining the prevalence of chlamydia infection in males and females attending a STD clinic, determining associated factors and identifying the most significant risk factors.

\section{Methods}

A cross-sectional, descriptive study was carried out at the Central STD Clinic of National STD/AIDS Control Programme, Sri Lanka from 1st December 2014 to 31st March 2015. Ethics approval was obtained from Ethics Review Committee, Medical Research Institute, Colombo.

Consecutive, males and females, above 18 years of age, who presented for screening, treatment or follow up of STDs were recruited. The population comprised of commercial sex workers (CSW), men who have sex with men (MSM) and people with high risk sexual behavior. Those who attended for follow up of previously diagnosed NGU/NGC and females with vaginal bleeding were excluded. The sample size was 163 females and 163 males, based on a prevalence of $12 \%$ (4) with a 0.05 precision and a confidence interval of $95 \%$.

\section{Data collection and laboratory procedure}

Endocervical swabs and urine were collected from females and males, respectively. In females, a Dacron(c) swab was inserted $1-2 \mathrm{~cm}$ into the endocervix followed by $2-3$ rotations and transported in universal transport medium (UTMRT, Copan, Italy). In males, $30-40 \mathrm{ml}$ of first pass urine was collected into a sterile container, at least two hours after previous urination. Specimens were stored at $-70{ }^{\circ} \mathrm{C}$. An intervieweradministered questionnaire was used to collect socio-demographic data, clinical features and STDrelated risk behavior. Examination and investigation findings were recorded. Symptomatic chlamydia infection was defined as infection with one or more of genital discharge, dysuria, genital itching, pelvic pain or dyspareunia.

Informed written consent was taken before administering the questionnaire, collecting the samples and extracting the clinical details. Details of the participants' identification was kept confidential.

Specimens were tested using the $\mathrm{COBAS}^{\circledR} \mathrm{TaqMan}^{\star}$ CT Test v2.0 (Roche Diagnostic Systems Inc., Branchburg, N.J.), a validated, CE (Conformité Européene), certified nucleic acid amplification test (NAAT) for the qualitative detection of C. trachomatis DNA from endocervical swabs in females and urine in males and females, targeting the chromosomal ompA gene and the cryptic plasmid that are common to all 15 C. trachomatis serovars including the Swedish variant (nvCT). The limit of detection is five copies of $C$. trachomatis DNA per PCR reaction.

\section{Data analysis}

Significance of putative associated factors were determined using the Pearson Chi-square test or Fisher's Exact test, with a $p$ value of 0.05 considered significant. The most significant risk factors were identified using a binary logistic model.

Results

Study population comprised 216 (46.2\%) females and $252(53.8 \%)$ males. The age range of females was 18-71 years with a median of 35 years [interquartile range (IQ) 27-43]. In males, the age range was 18-72 years with a median of 29 years (IQ 25-38).

The majority $(49.5 \%, \mathrm{n}=107)$ of females were married or living with a partner while the majority of males $(56.3 \%, \mathrm{n}=142)$ were unmarried. The female population included many CSW ( $\mathrm{n}=97,44.9 \%)$ with only one male CSW. In addition, 37 other females (17.1\%) and 205 males (81.3\%) were employed. Those who had had their first sexual encounter at $\leq 18$ years was $43.1 \%(n=93)$ and $22.7 \%,(n=56)$ in females and males, respectively. Almost all 
females $(99.5 \%, n=215)$ had only male partners. In males, available data $(\mathrm{n}=246)$ showed that the majority had only female partners $(73.6 \%, n=181)$ while homosexual and bi-sexual males accounted for $13 \%(n=32)$ and $13.4 \%(n=33)$. Available data ( $\mathrm{n}=204$ for females and $\mathrm{n}=225$ for males) showed that 95 females including 88 CSW (46.6\%), and 109 (48.4\%) males had multiple partners, ranging from 2-1000 in the previous year.

\section{Prevalence of chlamydia infection}

Overall, $17.1 \%(37 / 216)$ of females and 5.2\% $(13 / 252)$ of males were infected. Only $16.2 \%$ $(12 / 74)$ of symptomatic females and $11.6 \%(8 / 69)$ of symptomatic males were positive while the prevalence of chlamydia infection in asymptomatic females and males was $17.6 \%(25 / 142)$ and $2.7 \%$ (5/183). Among female sex workers (FSWs) $(n=97)$, $4 / 25(16 \%)$ of symptomatic and $16 / 72(22.2 \%)$ of asymptomatic were positive.

\section{Chlamydia infection in relation to socio- demographic factors}

The median age of infected females was 32 years (IQ 23.5-39.5) and that of infected males was 27 years (IQ 24.5-31.5). In females, the age group $\leq 25$ years $(28.5 \%, 12 / 42)$, females with no schooling $(28.6 \%, 4 / 14)$, unmarried females $(27.3 \%, 6 / 22)$, unemployed females $(26.6 \%, 4 / 15)$ and FSWs $(20.6 \%, 20 / 97)$ had the highest prevalence of infection. In males, the age group $\leq 25$ years had the highest prevalence $(7 \%, 5 / 71)$ and infection was more common in those widowed or separated or divorced $(14.2 \%, 2 / 14)$ and in men with education up to Grade 6-10 $(10.9 \%, 5 / 46)$ (Table 1$)$.

\section{Clinical presentation of chlamydia infection}

The majority of infected females $(67.5 \%, 25 / 37)$ were asymptomatic, including most infected FSW $(16 / 20,80 \%)$. In symptomatic patients $(n=12)$, vaginal discharge was the commonest symptom $(27 \%, 10 / 37)$ and cervical discharge $(40.5 \%, 15 / 37)$ was the commonest sign. In contrast, a majority of males positive for chlamydia infection were symptomatic $(61.5 \%, 8 / 13)$. Urethral discharge and dysuria/frequency were the commonest symptoms (38.5\%,5/13 each) and urethral discharge was the commonest sign $30.8 \%$ (4/13). In females presenting with vaginal discharge or urethral itching, only $16.4 \%(10 / 61)$ and $15.8 \%$ (3/19) were positive for chlamydia infection. In females with cervical discharge, $31.2 \%$ (15/42) were positive.
Table 1. Prevalence of chlamydia infection in relation to socio-demographic distribution

\begin{tabular}{|c|c|c|c|c|}
\hline \multirow{2}{*}{ Categories } & \multicolumn{2}{|c|}{ Females } & \multicolumn{2}{|c|}{ Males } \\
\hline & n/total & $\%$ & n/total & $\%$ \\
\hline \multicolumn{5}{|c|}{ Age group (years) } \\
\hline 20 & $3 / 11$ & 27.3 & $0 / 14$ & 0 \\
\hline $21-30$ & $13 / 63$ & 20.6 & $8 / 124$ & 6.4 \\
\hline $31-40$ & $14 / 77$ & 18.9 & $4 / 70$ & 5.7 \\
\hline $41-50$ & $3 / 46$ & 6.5 & $1 / 27$ & 3.7 \\
\hline 51 & $4 / 19$ & 21 & $0 / 17$ & 0 \\
\hline \multicolumn{5}{|l|}{ Age group } \\
\hline 25 years & $12 / 42$ & 28.5 & $5 / 71$ & 7.0 \\
\hline$>25$ years & $25 / 174$ & 14.4 & $8 / 181$ & 4.4 \\
\hline \multicolumn{5}{|c|}{ Marital status } \\
\hline Unmarried & $6 / 22$ & 27.3 & $8 / 142$ & 5.6 \\
\hline $\begin{array}{l}\text { Married/ } \\
\text { living } \\
\text { together }\end{array}$ & $13 / 107$ & 12.1 & $3 / 96$ & 3.1 \\
\hline $\begin{array}{l}\text { Widowed/ } \\
\text { separated/ } \\
\text { divorced }\end{array}$ & $18 / 87$ & 20.6 & $2 / 14$ & 14.2 \\
\hline \multicolumn{5}{|c|}{ Highest level of education } \\
\hline $\begin{array}{l}\text { No } \\
\text { schooling }\end{array}$ & $4 / 14$ & 28.6 & $0 / 3$ & 0 \\
\hline $\begin{array}{l}\text { Up to } \\
\text { grade } 5\end{array}$ & $10 / 41$ & 24.4 & $0 / 6$ & 0 \\
\hline Grade 6-10 & $9 / 79$ & 11.4 & $5 / 46$ & 10.9 \\
\hline GCE O/L & $8 / 43$ & 18.6 & $4 / 92$ & 4.3 \\
\hline GCE A/L & $6 / 34$ & 17.6 & $4 / 81$ & 4.9 \\
\hline Higher edu & $0 / 5$ & 0 & $0 / 24$ & 0 \\
\hline \multicolumn{5}{|l|}{ Occupation } \\
\hline Students & $0 / 3$ & 0 & $0 / 27$ & 0 \\
\hline Housewife & $7 / 64$ & 10.9 & - & - \\
\hline Retired & $0 / 0$ & 0 & $0 / 15$ & 0 \\
\hline Unemployed & $4 / 15$ & 26.6 & $0 / 4$ & 0 \\
\hline FSW & $20 / 97$ & 20.6 & $0 / 1$ & 0 \\
\hline Employed & $6 / 37$ & 16.2 & $13 / 205$ & 6.3 \\
\hline
\end{tabular}

In males presenting with a urethral discharge or dysuria/frequency, only $15.6 \%(5 / 32)$ and $11.6 \%$ (5/43) were positive, respectively. In males who had urethral discharge on examination, $16.7 \%(4 / 24)$ were positive (Table 2).

\section{Chlamydia infection and sexual and STD-related risk behavior}

In females, a higher prevalence of chlamydia infection was seen in those with age at first sex of $\leq 18$ years $(21.5 \%, 20 / 93$ vs $13.8 \%, 17 / 123)$. All infected females were heterosexual. Females who had worked as a CSW within the last one year or during last sex had a higher proportion of chlamydia infection $(20.9 \%, 19 / 91$ and $20.3 \%, 15 / 74$, respectively) vs 
those who had not done so $(15.5 \%, 18 / 116$ and $15.5 \%, 22 / 142$, respectively).

Females having sex with multiple partners during last three months, last one year and life time $(19.3 \%, 17 / 88,21.0 \%, 20 / 95$ and $18.8 \%, 25 / 133)$ had a higher prevalence than those with a single partner or abstinent $(15.6 \%, 20 / 128,14.0 \%, 17 / 121$ and $14.4 \%, 12 / 83)$.

All infected males had an age at first sex above 18 years. Heterosexual males had a higher prevalence $(6.6 \%, 12 / 181)$ than MSM $(1.5 \%, 1 / 65)$. Males who reported having sex with a CSW within the last one year or during last sex had a higher proportion of chlamydia infection than those with non-CSW partners within the last year or during last sex. Males who had sex with multiple partners during last three months, last one year and life time had a higher prevalence than those with a single partner or abstinent group (Table 3).

Table 2. Prevalence of chlamydia infection in relation to the clinical presentation

\begin{tabular}{|c|c|c|c|c|}
\hline \multirow{2}{*}{ Characteristics } & \multicolumn{2}{|c|}{ females } & \multicolumn{2}{|c|}{ males } \\
\hline & n/total & $\%$ & n/total & $\%$ \\
\hline \multicolumn{5}{|l|}{ Clinical presentation } \\
\hline Symptomatic & $12 / 74$ & 16.2 & $8 / 69$ & 11.6 \\
\hline Asymptomatic & $25 / 142$ & 17.6 & $5 / 183$ & 2.7 \\
\hline \multicolumn{5}{|c|}{ Clinical presentation among FSWs } \\
\hline Symptomatic & $4 / 25$ & 16 & - & - \\
\hline Asymptomatic & $16 / 72$ & 22.2 & - & - \\
\hline \multicolumn{5}{|l|}{ According to symptoms } \\
\hline Vaginal $^{\mathrm{a}} /$ urethral discharge $^{\mathrm{b}}$ & $10 / 61$ & 16.4 & $5 / 32$ & 15.6 \\
\hline Urethral itching & $3 / 19$ & 15.8 & - & - \\
\hline Dysuria/ frequency & $1 / 7$ & 14.3 & $5 / 43$ & 11.6 \\
\hline Dyspareunia $/$ rectal pain $^{\mathrm{b}}$ & $1 / 2$ & 50 & $0 / 1$ & 0 \\
\hline Pelvic pain ${ }^{\mathrm{a}} /$ scrotal pain $^{\mathrm{b}}$ & $0 / 2$ & 0 & $0 / 4$ & 0 \\
\hline \multicolumn{5}{|c|}{ According to the clinical signs } \\
\hline $\begin{array}{l}\text { Cervicala/urethral } \\
\text { discharge }^{\mathrm{b}}\end{array}$ & $15 / 48$ & 31.2 & $4 / 24$ & 16.7 \\
\hline Inflammatory cervix & $9 / 40$ & 22.5 & - & - \\
\hline Pelvic tenderness & $0 / 1$ & 0 & - & - \\
\hline
\end{tabular}

${ }^{a}$ females only ${ }^{b}$ males only

\section{Associated factors and the most significant risk factors for chlamydia infection}

Female gender was a significant associated factor for chlamydia infection $(\mathrm{p}=<0.001)$. In females, age $\leq 25$ years was associated with infection $(\mathrm{p}=0.029)$ but among males there was no association with age $\left(\mathrm{p}^{*}\right.$ value $\left.=0.526\right)$.
Table 3. Prevalence of chlamydia infection based on the sexual and STD-related risk behavior

\begin{tabular}{|c|c|c|c|c|}
\hline \multirow{2}{*}{ Characteristics } & \multicolumn{2}{|c|}{ females } & \multicolumn{2}{|c|}{ males } \\
\hline & n/total & $\%$ & n/total & $\%$ \\
\hline \multicolumn{5}{|l|}{ Age at first sex } \\
\hline 18 years & $20 / 93$ & 21.5 & $0 / 56$ & 0 \\
\hline$>18$ years & $17 / 123$ & 13.8 & $13 / 191$ & 6.8 \\
\hline \multicolumn{5}{|l|}{ Sex of partner } \\
\hline Male only & $37 / 215$ & 17.2 & $1 / 33$ & 3.0 \\
\hline Female only & $0 / 1$ & 0 & $12 / 181$ & 6.6 \\
\hline Male and female & - & - & $0 / 32$ & 0 \\
\hline MSM & - & - & $1 / 65$ & 1.5 \\
\hline \multicolumn{5}{|c|}{ Type of partner (last 12 months) } \\
\hline Commercial & $19 / 91$ & 20.9 & $5 / 41$ & 12.2 \\
\hline Non-commercial & $18 / 116$ & 15.5 & $6 / 189$ & 3.1 \\
\hline \multicolumn{5}{|c|}{ Type of partner at last sexual exposure } \\
\hline Commercial & $15 / 74$ & 20.3 & $4 / 24$ & 16.7 \\
\hline Non-commercial & $22 / 142$ & 15.5 & $9 / 221$ & 4.1 \\
\hline \multicolumn{5}{|c|}{ Number of partner last 3 months } \\
\hline $\begin{array}{l}\text { None or one } \\
\text { partner }\end{array}$ & $20 / 128$ & 15.6 & $10 /$ & 5.2 \\
\hline & & & 191 & \\
\hline Multiple partners & $17 / 88$ & 19.3 & $3 / 55$ & 5.4 \\
\hline \multicolumn{5}{|c|}{ Multiple partners ( more than one partner last year) } \\
\hline $\begin{array}{l}\text { None or one } \\
\text { partner }\end{array}$ & $17 / 121$ & 14.0 & $6 / 137$ & 4.4 \\
\hline Multiple partners & $20 / 95$ & 21.0 & $5 / 109$ & 4.6 \\
\hline \multicolumn{5}{|c|}{ Number of partners life time } \\
\hline $\begin{array}{l}\text { None or one } \\
\text { partner }\end{array}$ & $12 / 83$ & 14.4 & $3 / 64$ & 4.7 \\
\hline Multiple partners & $25 / 133$ & 18.8 & $10 / 182$ & 5.5 \\
\hline
\end{tabular}

Beinga CSW was associated with chlamydia infection $(p=<0.001)$. In females, there was no association of infection with symptoms $(\mathrm{p}=0.797)$ including in CSWs $(\mathrm{p}=0.508)$. In contrast, symptomatic males were more likely to be infected than asymptomatic $\left(\mathrm{p}^{*}=0.009\right)$. Although infection was more prevalent among females with age at first sex $\leq 18$ this was not statistically significant $(\mathrm{p}=0.21)$. Providing or receiving commercial sex in the last year or at last sex was significantly associated with infection ( $p=0.002$ each). Having multiple partners was not associated with infection $(\mathrm{p}=0.505)$. Being a MSM was not a significant associated factor $\left(\mathrm{p}^{*}=0.193\right)$ (Table 4).

Females had a 3.94 times higher risk for chlamydia infection than males. Younger people ( $\leq 25$ years) had a 2.14 times risk. Those who provided or received commercial sex had a 1.98 times risk (Table 5). 
Table 4. Factors associated with chlamydia infection

\begin{tabular}{|c|c|c|c|c|c|}
\hline \multirow{2}{*}{ Characteristics } & \multicolumn{2}{|c|}{ Positive } & \multicolumn{2}{|c|}{ Negative } & \multirow{2}{*}{$\begin{array}{l}\text { Significance } \\
(p \text { value })\end{array}$} \\
\hline & $\mathbf{N}$ & $\%$ & $\mathbf{N}$ & $\%$ & \\
\hline \multicolumn{6}{|l|}{ Sex } \\
\hline Female & 37 & 17.1 & 179 & 82.9 & \multirow{2}{*}{$p<0.001$} \\
\hline Male & 13 & 5.2 & 239 & 94.8 & \\
\hline \multicolumn{6}{|l|}{ Age - females } \\
\hline 25 years & 12 & 32.4 & 30 & 16.8 & \multirow{2}{*}{$p=0.029$} \\
\hline$>25$ years & 25 & 67.6 & 149 & 83.2 & \\
\hline \multicolumn{6}{|l|}{ Age - males } \\
\hline 25 years & 5 & 38.5 & 66 & 27.6 & \multirow{2}{*}{$p^{*}=0.526$} \\
\hline$>25$ years & 8 & 61.5 & 173 & 72.4 & \\
\hline \multicolumn{6}{|c|}{ Highest level of education } \\
\hline Up to grade 10 & 24 & 48 & 148 & 35.4 & \multirow{2}{*}{$p=0.081$} \\
\hline Above grade 10 & 26 & 52 & 270 & 64.6 & \\
\hline \multicolumn{6}{|l|}{ Occupation } \\
\hline CSW & 20 & 20.4 & 78 & 79.6 & \multirow{2}{*}{$p<0.001$} \\
\hline Non CSW & 30 & 8.1 & 340 & 91.9 & \\
\hline \multicolumn{6}{|c|}{ Clinical presentation- female } \\
\hline Symptomatic & 12 & 32.4 & 62 & 34.6 & \multirow{2}{*}{$p=0.797$} \\
\hline Asymptomatic & 25 & 67.6 & 117 & 65.4 & \\
\hline \multicolumn{6}{|c|}{ Clinical presentation - male } \\
\hline Symptomatic & 8 & 61.5 & 61 & 25.5 & \multirow{2}{*}{$p^{*}=0.009$} \\
\hline Asymptomatic & 5 & 38.5 & 178 & 74.5 & \\
\hline \multicolumn{6}{|c|}{ Clinical presentation among FSW } \\
\hline Symptomatic & 4 & 20 & 21 & 26.9 & \multirow{2}{*}{$p=0.508$} \\
\hline Asymptomatic & 16 & 80 & 56 & 72.7 & \\
\hline \multicolumn{6}{|l|}{ Age at first sex } \\
\hline 18 years & 20 & 40 & 129 & 31.2 & \multirow{2}{*}{$p=0.210$} \\
\hline$>18$ years & 30 & 60 & 284 & 68.8 & \\
\hline \multicolumn{6}{|c|}{ Type of partner (last 12 months) } \\
\hline Commercial & 24 & 50 & 108 & 27.8 & \multirow{2}{*}{$p=0.002$} \\
\hline Non-commercial & 24 & 50 & 281 & 72.2 & \\
\hline \multicolumn{6}{|c|}{ Type of partner at last sexual exposure } \\
\hline Commercial & 19 & 38 & 79 & 19.2 & \multirow{2}{*}{$p=0.002$} \\
\hline Non-commercial & 31 & 62 & 332 & 80.2 & \\
\hline Multiple partners & ore $t$ & one p & ner las & rear) & \\
\hline $\begin{array}{l}\text { None or one } \\
\text { partner }\end{array}$ & 23 & 47.9 & 202 & 53 & $p=$ \\
\hline Multiple partners & 25 & 52.1 & 179 & 47 & 0.505 \\
\hline Sub-categories of $p$ & ticip & & & & \\
\hline MSM & 1 & 1.5 & 64 & 98.5 & $t^{*}=0193$ \\
\hline Non MSM & 12 & 6.4 & 175 & 93.6 & $P-0.190$ \\
\hline
\end{tabular}

\section{Discussion}

Studies on female STD clinic attendees have shown a widely varying prevalence of chlamydia infection. (10-12) In Spain, this population had an infection rate of $4.5 \%$. (10)
Table 5. The most significant risk factors for genital chlamydia infection

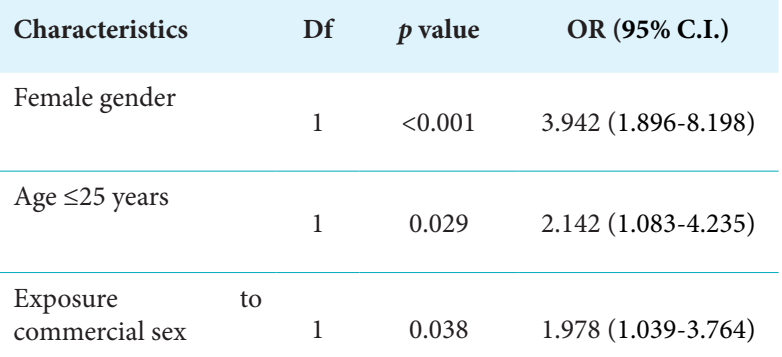

OR $=$ Odds Ratio, C.I. $=$ Confidence Interval

However, the same population had a much higher prevalence rate in Brazil (11) and Taiwan (12) (20.7\% and $22.8 \%$, respectively). In Sri Lanka, a study in 1998 at the same clinic using antigen detection and culture, revealed a $12 \%$ positivity rate for males and females.(4) In a Sri Lankan study, where endocervical swabs were tested using a NAAT, the prevalence among female attendees of the Central STD Clinic and the STD Clinic at the Colombo South Teaching Hospital was 8.3\%.(8) Similarly, a study on STD Clinic female attendees of the Colombo North Teaching Hospital reported a prevalence of $8.2 \%$.(9) The $17.1 \%$ prevalence of chlamydia infection in females detected in our study is similar to the rates seen in Brazil and Taiwan and much higher than those recorded in previous Sri Lankan studies.

Studies in different countries show different rates of prevalence of chlamydia infection in FSWs. A study in Spain detected infection in $4.7 \%$ of street-based FSWs (10) while a study done in Sri Lanka found a prevalence of $15.4 \%$ in FSWs.(8) The prevalence of infection in FSWs in the present study is much higher (20.6\%). The reason for the higher prevalence rates in this study may be the use of more sensitive tests or reflect a true increase in infection rates.

In England, in 2014, among males attending a genitourinary clinic, $21 \%$ were diagnosed with chlamydia infection.(13) However, the present study revealed a relatively low rate of infection $(5.2 \%)$ in males.

The STD clinics in Sri Lanka follow a modified version of the WHO syndromic approach for treatment of genital infection. (14) In this approach, men and women are treated based on the presence of symptoms and signs and on the results of smears of cervical, urethral and urine deposits. A study in New Delhi showed that the prevalence of infection among symptomatic females was only $19.9 \%$. (15) 
A study in the USA, among symptomatic males, found that only $13.5 \%$ of them were positive for chlamydia.(16) Similarly, in the present study only $16.2 \%$ of symptomatic females and $11.6 \%$ of symptomatic males were infected. Conversely, the rate of chlamydia infection among asymptomatic clients attending STD clinics for other complaints can be quite high. Among 100 asymptomatic FSWs in Ghana, 19\% were positive for chlamydia.(17) In the present study, too, there was a high prevalence of chlamydia infection in asymptomatic females $(17.6 \%)$, with as many as $22.2 \%$ of asymptomatic FSWs infected. However, the rate of infection in asymptomatic men was only $2.7 \%$. In females, there was no association of chlamydia infection with the presence or absence of symptoms ( $\mathrm{p}=0.797)$. This lack of association was seen even in FSWs ( $\mathrm{p}=0.508$ ). In contrast, symptomatic males were more likely to be infected than asymptomatic $\left(\mathrm{p}^{*}=0.009\right)$. This suggests that the syndromic approach to diagnosis may not be suitable for chlamydia infection, especially in females.

The occurrence of asymptomatic chlamydia infection among females is $70 \%$. $(18,19)$ The present study, too, showed that $67.5 \%$ of infected females were asymptomatic. While a study in Hong Kong showed that $65.6 \%$ of positive FSWs were asymptomatic (20), in the present study as much as $80 \%$ of infected FSWs were asymptomatic. Women with asymptomatic infections are unlikely to seek treatment and are an important reservoir of infection. Asymptomatic FSW contribute to the spread of infection in the community. In contrast, the rate of asymptomatic chlamydia infection in males is considerably lower, at around $50 \%$. $(18,19)$ In the present study, asymptomatic infection in males was even lower (38.5\%). This may be because the study was carried out in a STD clinic population and biased towards symptomatic males.

Similar to a Swedish study (21) in which females were shown to be at a higher risk of chlamydia infection than males [adjusted odds ratio (AOR) of $1.6(0.3-7.8)]$, the present study found that females have a higher risk with an OR=3.942 (95\% CI 1.8968.198). In the same Swedish study, females aged $\leq 25$ years were at a higher risk of chlamydia infection with an AOR of 1.7 (0.6 - 4.8). A Sri Lankan study calculated that the risk of infection among females $\leq 25$ years was 1.06 (95\% CI 0.9-12.41).(8) Similarly, in the present study, the highest prevalence of chlamydia infection was found in the $\leq 25$ year age group, in both males and females and being $\leq 25$ years was a significant risk factor for chlamydia infection in females $(\mathrm{p}=0.029, \mathrm{OR}=2.142(1.083-4.235)$. This may be due to young women having a tendency for cervical ectopy at the squamo-columnar junction exposing susceptible cells to the organism.

Early age at first sex is a known risk factor for STD. A study done in Scotland found a significant association between chlamydia infection and age at first sex $\leq 18$ years $(p=0.006, \mathrm{OR}=1.91,95 \% \mathrm{CI} 1.16$ 3.12).(22) However, in our study, early age at first sex was not associated with infection $(p=0.21)$.

It is evident that chlamydia infection is more common in those who have multiple sexual partners. A Sri Lankan study found that as many as $14 \%$ of females who had more than one sexual partner were infected. (8) Similarly, in the present study, the subgroups having sex with multiple partners had a high prevalence of infection vs those who had only a single partner or were abstinent but this difference was not significant $(\mathrm{p}=0.505)$. In a Scottish study, the prevalence of chlamydia in heterosexual and homosexual men was $14.6 \%$ and $2.4 \%$, respectively.(22) In the present study the rates were $6.6 \%$ and $1.5 \%$, respectively. Prevalence of chlamydia among MSM in UK was $3-10.5 \%$. (14) A study done in Spain has shown that prevalence among MSM, detected by NAATs using first-void urine, was $4.5 \% .(10)$ The present study revealed a very low prevalence of chlamydia infection of $1.5 \%$ among MSM.

In a study done in Vietnam, the prevalence of chlamydia was higher among FSWs but this was not statistically significant $(p=0.08) .(23)$ In contrast, our study showed a significant association between being a FSW and chlamydia infection $(\mathrm{p}<0.001)$ and, giving or receiving commercial sex carried a high risk of $(\mathrm{p}=0.002)(\mathrm{OR}=1.978,95 \%$ CI 1.039 $-3.764)$.

\section{Conclusion}

Prevalence of chlamydia infection among female attendees is high and many are asymptomatic, which may contribute to unrecognized transmission in the community. Among females, prevalence of infection in the symptomatic group was low and a high proportion of infections were asymptomatic rendering syndromic management inappropriate. A high prevalence of infection, mostly asymptomatic, was noted among FSWs and giving or receiving commercial sex was a significant risk for chlamydia infection. This is probably the driver of the epidemic of chlamydia. Prevalence of infection in the general population should be determined in a future study 
in order to assess the burden in the community. Until such time, targeted screening for chlamydia should be instituted among FSWs and the highrisk group (young females $\leq 25$ years) of the general population.

\section{References}

1. Centers for Disease Control and Prevention. Chlamydial Infections in Adolescents and Adults. Centers for Disease Control and Prevention, 2015 http://www.cdc.gov/std/ tg2015/chlamydia.htm.

2. Bennett JE, Dolin R, Blaser MJ. Mandell, Douglas and Bennett's Principles and Practice of Infectious Diseases. 8th ed. Philadelphia: Elsevier, 2015.

3. Newman L, Rowley J, Vander Hoorn S, et al. Global Estimates of the Prevalence and Incidence of Four Curable Sexually Transmitted Infections in 2012 Based on Systematic Review and Global Reporting. PLoS One 2015; 10: 12 .

4. Galagoda GCS. Detection of Chlamydia trachomatis in patients attending the sexually transmitted disease clinic with non-gonococcal urethritis. MD dissertation. 1998.

5. Samarakoon S. Sexually transmitted diseases among female sex workers attending the Central Venereal diseases clinic, Colombo. MD dissertation. 1991.

6. Gunaratne CD. Prevalence of gonorrhoea and Chlamydia trachomatis infection in pregnancy. MD dissertation. 1990.

7. Palihawadana TS, Dissanayake DMAB, Harshanie A, Wijesinghe PS. Chlamydia trachomatis infection in an infertile population: a cross-sectional study. Sri Lanka Journal of Obstetrics and Gynaecology 2010; 32: 85-88.

8. Mangalika GHAK, Cankanamge SKC, Priyadarshana D, et al. Prevalence of Chlamydia trachomatis in women attending sexually transmitted disease clinics in the Colombo district, Sri Lanka. Indian J Pathol Microbiol 2014; 57(1): 55-60.

9. Samarawickrema NA, Tabrizi SN, Young E, Gunawardena P, Garland SM. Prevalence of Trichomonas vaginalis, Chlamydia trachomatis, Neisseria gonorrhoeae and human papillomavirus in a sexual health clinic setting in urban Sri Lanka. Int J STD AIDS 2015; 26(10): 733-739.

10. Vall-Mayans M, Villa M, Saravanya $M$, et al. Sexually transmitted Chlamydia trachomatis, Neisseria gonorrhoeae, and HIV-1 infections intwo at-risk populations in Barcelona: female street prostitutes and STI clinic attendees. Int J Infect Dis 2007 Mar; 11(2): 115-122.

11. Santos C, Teixeira F, Vicente A, Filho SA. Detection of Chlamydia trachomatis in Endocervical Smears of Sexually Active Women in Manaus-AM, Brazil, by PCR Braz J Infect Dis 2003; 7(2): 91-95.

12. 14.Kow-Tong C, Shou-Chien C, Chien-Chou C, LanHui L, Li-Hui T. Chlamydial infection among patients attending STD and genitourinary clinics in Taiwan. BMC Public
Health 2007; 7:120.

13. Health Protection Report. Sexually trasmitted Infection and Chlamydia screening in England, 2014. Public Health England, 2015.

14. World Health Organization. Guideline for the management of Sexually Transmitted Infections. World Health Organization, 2003.

15. Malhotra M, Bala M, Muralidhar S, Khunger N, Puri P. Prevalence of sexually transmitted infections in patients attending a tertiary care hospital in North India -a retrospective Study. Indian J Sex Transm Dis 2008; 29: 82-85.

16. Wiesenfeld HC, Hillier SL, Krohn MA, Landers DV, Sweet RL. Bacterial Vaginosis Is a Strong Predictor of Neisseria gonorrhoeae and Chlamydia trachomatis Infection. Clin Infect Dis 2003; 36: 663-8.

17. Abubakari A, Osei-Djarbeng SN, Larbi JA, Frimpong EH. Presence of chlamydia infection among asymptomatic female commercial sex-workers (CSWs) in the Kumasi Metropolis, Ghana. Int J Curr Microbiol App Sci 2016; 5(1): 342-349.

18. World Health Organization. (2001) Global Prevalence and Incidence of Selected Curable Sexually Transmitted Infections: Overview and Estimates. World Health Organization.

19. UK national guideline for the management of infection with Chlamydia trachomatis. 2015.

20. Mak KH. Genital Chlamydia Trachomatis Infection in Commercial Sex Workers Attending a Sexually Transmitted Disease Clinic in Hong Kong. Hong Kong Dermatology \& Venereology Bulletin. 1998.

21. Steiner AS, Hallera DM, Elgerb BS, Seboa P, Gaspoza JM, Wolff H. Chlamydia trachomatis infection in a Swiss prison:a cross sectional study. Swiss Medical Weekly 2010; 140: 13126.

22. Dixon L, Pearson S, Clutterbuck DJ. Chlamydia trachomatis infection and nongonococcal urethritis in homosexual and heterosexual men in Edinburgh. Int J STD AIDS 2002; 13: $425-426$

23. Nguyen TV, Khuu NV, Thile TT, et al. Sexually Transmitted Infections and Risk Factors for Gonorrhea and Chlamydia in Female Sex Workers in Soc Trang, Vietnam. Sex Transm Dis 2008 Nov; 35(11): 935-940. 